\title{
The response to extracytoplasmic stress in Escherichia coli is controlled by partially overlapping pathways
}

\author{
Lynn Connolly, ${ }^{1}$ Alejandro De Las Peñas, ${ }^{2,3}$ Benjamin M. Alba, ${ }^{1}$ and Carol A. Gross ${ }^{3,4}$ \\ ${ }^{1}$ Department of Biochemistry and Biophysics and ${ }^{3}$ Departments of Stomatology and Microbiology, University of California, \\ San Francisco (UCSF), San Francisco, California 94143 USA; ${ }^{2}$ Department of Bacteriology, University of Wisconsin- \\ Madison, Madison, Wisconsin 53706 USA
}

The activity of the altemate $\sigma$-factor $\sigma^{\mathrm{E}}$ of Escherichia coli is induced by several stressors that lead to the extracytoplasmic accumulation of misfolded or unfolded protein. The $\sigma^{\mathrm{E}}$ regulon contains several genes, including that encoding the periplasmic protease DegP, whose products are thought to be required for maintaining the integrity of the cell envelope because cells lacking $\sigma^{\mathrm{E}}$ are sensitive to elevated temperature and hydrophobic agents. Selection of multicopy suppressors of the temperature-sensitive phenotype of cells lacking $\sigma^{\mathrm{E}}$ revealed that overexpression of the lipoprotein NIpE restored high temperature growth to these cells. Overexpression of NIpE has been shown previously to induce DegP synthesis by activating the Cpx two-component signal transduction pathway, and suppression of the temperature-sensitive phenotype by $\mathrm{NIpE}$ was found to be dependent on the Cpx proteins. In addition, a constitutively active form of the CpxA sensor/ kinase also fully suppressed the temperature-sensitive defect of cells lacking $\sigma^{\mathrm{E}}$. DegP was found to be necessary, but not sufficient, for suppression. Activation of the C px pathway has also been shown to al leviate the toxicity of several LamB mutant proteins. Together, these results reveal the existence of two partially overlapping regulatory systems involved in the response to extracytoplasmic stress in $E$. coli.

[Key Words: rpoE; stress response; cpxRA; outer membrane; nlpE; peri plasm]

Received March 7, 1997; revised version accepted June 9, 1997.

The response to misfolded or unfolded protein is one of the most highly conserved regulatory responses among all organisms. When exposed to stressors such as heat or ethanol, all cells undergo the transcriptional induction of a conserved set of genes known as the heat shock genes, which are required to combat cellular stress (Bukau 1993; Yura et al. 1993; Becker and Craig 1994; Georgopoulos et al. 1994; Gross 1996). The majority of these genes encode proteins such as chaperones or proteases that act to either refold, prevent aggregation, or degrade mi sfol ded protein (Bukau 1993; Y ura et al. 1993; Becker and Craig 1994; Georgopoulos et al. 1994; Gross 1996).

In addition to being highly conserved, the stress response is compartmentalized into separate pathways that regulate protein-folding processes in different subcellular compartments (McMillan et al. 1994). For example, the cytoplasmic stress response in eukaryotes is coordinated by a family of transcriptional activators known as the heat shock transcription factors (HSFs) (Wu 1995; M orimoto et al. 1996). A separate pathway for

${ }^{4}$ Corresponding author.

E-MAIL cgross@cgl.ucsf.edu; FAX (415) 476-4204. the response to the accumulation of misfolded protein in the endoplasmic reticulum, known as the unfolded protein response (UPR) (M CM illan et al. 1994; Shamu et al. 1994), is controlled by a novel signal transduction pathway (Cox et al. 1993; M ori et al. 1993; Cox and Walter 1996; Sidrauski et al. 1996). In this way, cells can respond to insults that affect only a single subcel lular compartment without inducing a cell-wide response.

In Escherichia coli, the stress response is compartmentalized into cytoplasmic and extracytoplasmic responses. The cytoplasmic response is coordinated by the alternate $\sigma$-factor $\sigma^{32}$ (Grossman et al. 1984; Landick et al. 1984; Yura et al. 1984), which responds to the accumulation of misfol ded protein by directing the transcription of a well-characterized set of genes, including those encoding the DnaK/Dnal chaperone complex (Bukau 1993; Y ura et al. 1993; Becker and Craig 1994; Georgopoul os et al. 1994; Gross 1996). These chaperones, in turn, are thought to down-regulate $\sigma^{32}$ activity upon relief of cytoplasmic stress (Straus et al . 1989, 1990; Gamer et al. 1992, 1996; Liberek et al. 1992; Liberek and GeorgopouIos 1993).

In contrast, the extracytoplasmic response is less well defined and is believed to be controlled by at least two signal transduction systems, the Cpx two-component system and the $\sigma^{\mathrm{E}}$-mediated system. The Cpx system, 
composed of an inner membrane sensor kinase encoded by cpxA and a response regulator encoded by $c p x R$, is activated by either overexpression of the outer membrane lipoprotein N IpE (Gupta et al. 1995; Snyder et al. 1995) or mutational activation of CpxA (Cosma et al. 1995; Danese et al. 1995; Snyder et al. 1995). U pon activation of the Cpx system, the envel ope-associated toxicity of certain LamB mutant proteins is suppressed by inducing synthesis of the periplasmic protease DegP (Cosma et al . 1995; Snyder et al. 1995). The physi ological signal inducing this pathway remains to be definitively identified. Because cells lacking the C px pathway have no obvious phenotype (Danese et al. 1995; L. Connolly, unpubl.), the cellular role of this signal transduction system remains obscure.

The second periplasmic stress response system is coordinated by the heat and ethanol responsive alternate $\sigma$-factor, $\sigma^{\mathrm{E}}$. In addition to being induced by these general stresses, the $\sigma^{\mathrm{E}}$ pathway is uniquely induced in response to alterations in the expression or maturation of a class outer membrane proteins (OM Ps) called the porins (M ecsas et al. 1993). The porins undergo a complex series of folding and oligomerization steps prior to being inserted into the outer membrane (Pugsley 1993), and al terations in this pathway lead to a buildup of folding intermediates that are believed to be sensed by the $\sigma^{\mathrm{E}}$ pathway (M ecsas et al. 1993; Rouvière and Gross 1996). This signal is transduced to $\sigma^{\mathrm{E}}$ by RseA, a $\sigma^{\mathrm{E}}$-specific anti- $\sigma$ factor located in the inner membrane, and a periplasmic protein, RseB (De Las Peñas et al. 1997; Missiakas et al. 1997). Activation of $\sigma^{\mathrm{E}}$, in turn, leads to the induction of at least 10 different proteins, 4 of which have been definitively identified: the periplasmic protease DegP, the second heat shock $\sigma$-factor, $\sigma^{32}$, the peri plasmic peptidyl prolyl isomerase FkpA, and $\sigma^{\mathrm{E}}$ itself (Erickson et al. 1987; Lipinska et al . 1988; Erickson and Gross 1989; Wang and Kaguni 1989; Raina et al. 1995; Rouvière et al. 1995; Danese and Silhavy 1997). Genes under the control of $\sigma^{\mathrm{E}}$ are believed to encode functions required for the maintenance of envel ope integrity under stress conditions because cells lacking $\sigma^{\mathrm{E}}$ are sensitive to el evated temperature, SDS/EDTA, and crystal violet (Hiratsu et al. 1995; Raina et al. 1995; Rouvière et al. 1995). In an attempt to isolate either genes downstream of $\sigma^{\mathrm{E}}$ or components of other signal transduction cascades capable of relieving periplasmic stress, we isol ated genes that when overexpressed were capable of restoring growth at high temperature to cells lacking $\sigma^{\mathrm{E}}$.

\section{Results}

Selection and identification of a suppressor plasmid

To isol ate genes capable of restoring growth at high temperature to cells lacking $\sigma^{\mathrm{E}}$, rpoE ${ }^{-}$cells were transformed with a genomic library containing DNA prepared from the prototypic wild-type E. coli strain MG1655. Following phenotypic expression at $30^{\circ} \mathrm{C}$, one-tenth of the cells were plated at $30^{\circ} \mathrm{C}$ for viable count, and the remainder at $42^{\circ} \mathrm{C}$ for the selection of temperature-resistant candi- dates. Of a total of $3.7 \times 10^{5}$ possi ble transformants, 423 temperature-resistant suppressor candidates were identified. Because our recipient strain contains a lacZ reporter gene, which is exclusively transcribed by holoenzyme containing $\sigma^{\mathrm{E}}$ (M ecsas et al. 1993), we were able to identify and discard transformants containing wild-type rpoE sequences by screening on X-gal. Plasmid DN A was then purified from white candidate colonies and retransformed into the original $\mathrm{rpoE}^{-}$strain to ensure that the temperature-resistant phenotype was plasmid dependent. After retransformation, one candidate plasmid, pBA 25, retained suppressor ability. Remarkably, pBA25 raised the plating efficiency of the parental strain four orders of magnitude, from $4.2 \times 10^{-5}$ for cells containing vector alone to 0.6 (Fig. 1).

\section{Mapping and sequence analysis}

To determine the region of the genome located on the suppressor plasmid, sequence was obtained from either end of the insert using vector-based primers. The sequence was then subjected to a BLAST search (Altschul et al. 1990). This analysis reveal ed that the plasmid contained three full open reading frames (ORF) and a partial ORF mapping to minute 4.7 of the $\mathrm{E}$. coli chromosome. The insert size, restriction map (data not shown), and identity of sequences at either end of the insert indi cated that only one insert was contained in the plasmid. The insert encodes the ORFs yae, yaeF, and the recently described gene $\mathrm{nlpE}$ in addition to a partial copy of the drpA/proS gene (Fig. 1).

Deletion of yaeF and drpA/proS by removal of the AflII-Xbal fragment reveal ed that the segment containing yaej and $\mathrm{nlpE}$ was responsible for suppression of the temperature-sensitive defect (Fig. 1). Overexpression of $\mathrm{nlpE}$ has recently been shown to induce expression of the periplasmic protease DegP by activating the C px twocomponent signal transduction pathway (Danese et al. 1995). degP is also a member of the $\sigma^{\mathrm{E}}$ regulon, and we reasoned that $\mathrm{nlpE}$ might be suppressing $\mathrm{rpoE}^{-}$cells by activating this pathway, leading to the induction of degP.

To determine whether $\mathrm{nlpE}$ alone was capable of re storing growth to $\mathrm{rpoE}^{-}$cells at high temperature in the absence of yaeJ, nlpE was PCR amplified from the original suppressor plasmid and placed under the control of the lac promoter. nlpE alone retained the ability to rescue the temperature-sensitive phenotype of the parental $\mathrm{rpoE}^{-}$strain (Fig. 1), indicating that overexpression of $\mathrm{nlpE}$ is responsible for suppression.

During the course of characterizing pBA25, we discovered a single restriction digest change in $\mathrm{nlpE}$ that could potentially change the coding sequence of the protein. To ensure that any mutations in the nlpE allele we isolated were not responsible for suppressor activity, we introduced plasmid pLD404 (Snyder et al. 1995), which carries a known wild-type all el e of $\mathrm{nlpE}$, into the ori gi nal $\mathrm{rpoE}^{-}$strain. rpoE ${ }^{-}$cells containing pLD404 plated with similar efficiency at $42^{\circ} \mathrm{C}$ as cells containing plasmids derived from the original suppressor plasmid (Fig. 1). 


\section{Connolly et al.}

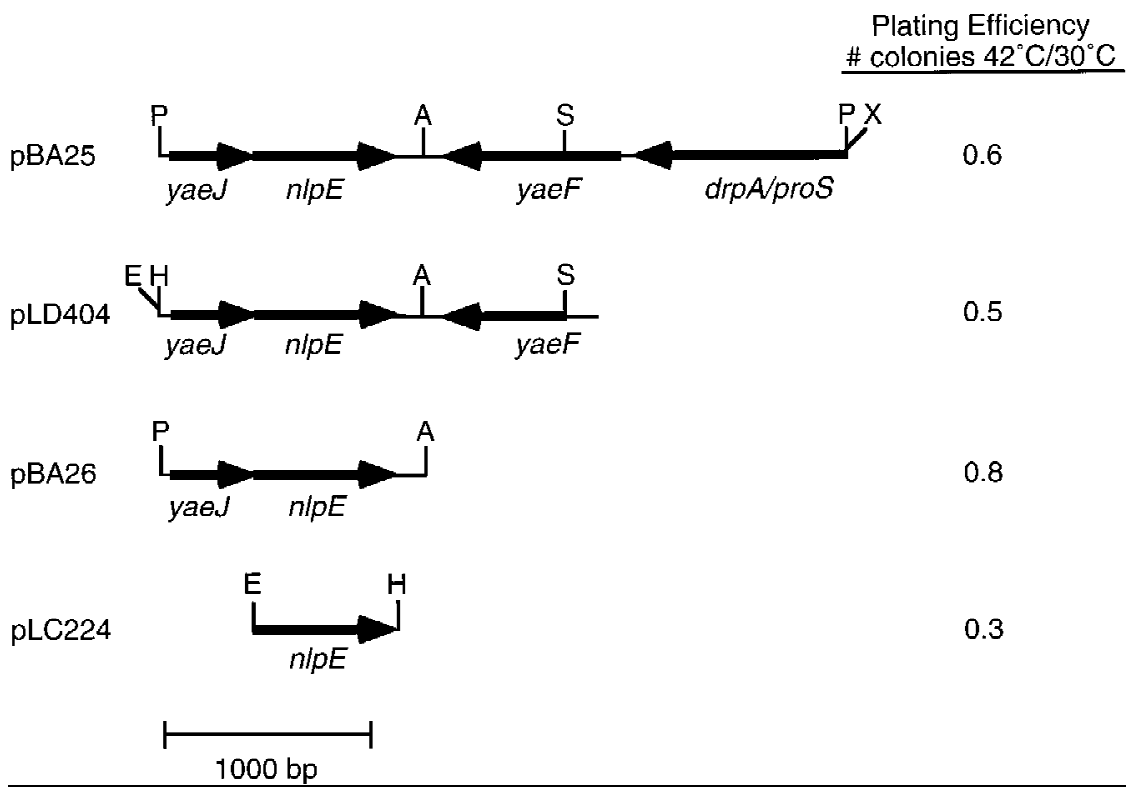

This result indicates that wild-type nlpE suppresses the temperature-sensitive phenotype of $\mathrm{rpoE}^{-}$cells and that any mutations present within the allele of $\mathrm{nlpE}$ originally isolated are not responsible for suppression.

\section{Mechanism of suppression}

To determine whether $\mathrm{nlpE}$ requires the $\mathrm{Cpx}$ pathway for suppression, we constructed $\mathrm{rpoE}^{-} \mathrm{cpxA}^{-}$mutant strains and asked whether nlpE-containing plasmids could restore growth at high temperature to these double mutant cells. As shown in Table 1, although cells lacking both $\sigma^{\mathrm{E}}$ and the $\mathrm{Cpx}$ pathway plate with equal efficiency at $42^{\circ} \mathrm{C}$ as cells lacking $\sigma^{\mathrm{E}}$ al one $\left(1.9 \times 10^{-5} \mathrm{vs}\right.$. $1.1 \times 10^{-5}$ ), plasmids containing $\mathrm{nl} \mathrm{pE}$ were no longer able to suppress the temperature sensitive phenotype. These results demonstrate that $\mathrm{N} I \mathrm{pE}$ requires the C px pathway for suppression of the temperature-sensitive phenotype

Table 1. Plating efficiency of $\mathrm{rpoE}^{-}$strains lacking the Cpx pathway

\begin{tabular}{lllc}
\hline Strain & \multicolumn{1}{c}{ Genotype } & Plasmid & $\begin{array}{c}\text { Plating efficiency } \\
\text { (no. of colonies } \\
\text { at } 42^{\circ} \mathrm{C} / 30^{\circ} \mathrm{C} \text { ) }\end{array}$ \\
\hline CAG22700 & rpoE:: $\Omega \mathrm{cm}$ recA56 & none & $1.1 \times 10^{-5}$ \\
CAG33126 & CAG22700 & vector & $4.2 \times 10^{-5}$ \\
CAG33127 & CAG22700 & pnlpE & 0.6 \\
CAG33091 & rpoE:: $\Omega$ Cm & none & $1.9 \times 10^{-5}$ \\
& cpxR:::Sp & & \\
CAG33239 & CAG33091 & vector & $<1.6 \times 10^{-8}$ \\
CAG33240 & CAG33091 & pnlpE & $<3.9 \times 10^{-8}$
\end{tabular}

The plating efficiency of each strain was determined as described in M aterials and M ethods. Vector-containing cells carry pUC18; pnlpE represents pBA25. of cells lacking $\sigma^{\mathrm{E}}$. One caveat to these experiments is that the vector al one decreased the plating efficiency of the double mutant strain 1000-fold. $\beta$-Lactamase expression from these $A p^{R}$ plasmids may constitute a second periplasmic stressor that might interfere with any re sidual suppression by $\mathrm{nl} \mathrm{pE}$ in the $\mathrm{Cpx}^{-}$background.

The requirement of the Cpx pathway for suppression by $\mathrm{N}$ IpE indicated that $\mathrm{N}$ I $\mathrm{pE}$ was probably acting via the $\mathrm{Cpx}$ proteins to suppress the $\mathrm{rpoE}^{-}$temperature-sensitive phenotype. If this were true, then other conditions that activate this pathway should similarly suppress the $\mathrm{rpoE}^{-}$temperature-sensitive phenotype. To test this hypothesis, we introduced a gain-of-function allel e of cpxA (срхA*) (Cosma et al. 1995; Danese et al. 1995) into the original $\mathrm{rpoE}^{-}$strain and asked whether mutational activation of the Cpx pathway would suppress the $\mathrm{rpoE}^{-}$ cells to the same extent as overexpression of $\mathrm{nlpE}$. $\mathrm{rpoE}^{-}$ cells containing the cpXA* allele plated with the same efficiency at $42^{\circ} \mathrm{C}$ as cells overexpressing nlpE (Fig. 2, lanes 2,4 ), indicating that activation of the $C p x$ pathway suppresses the temperature-sensitive phenotype.

\section{DegP is required, but not sufficient, for suppression}

$\mathrm{Cpx}$ and $\sigma^{\mathrm{E}}$ both regulate the expression of the periplasmic protease DegP. We reasoned that activation of the Cpx pathway might be suppressing the $\mathrm{rpoE}^{-}$phenotype by simply restoring expression of a single gene in the rpoE regulon, degP, and decided to test whether degP was both required and sufficient for suppression.

To test whether degP was required for suppression of the rpoE ${ }^{-}$phenotype by the C $\mathrm{px}$ pathway, we introduced a degP null allele into $\mathrm{rpoE}^{-}$cells containing the cpxA* allele. Introduction of a degP null allele into $\mathrm{rpoE}^{-}$cells reduced the plating efficiency 1500 -fold, and subsequent introduction of the cpxA* al lele did not restore growth at 


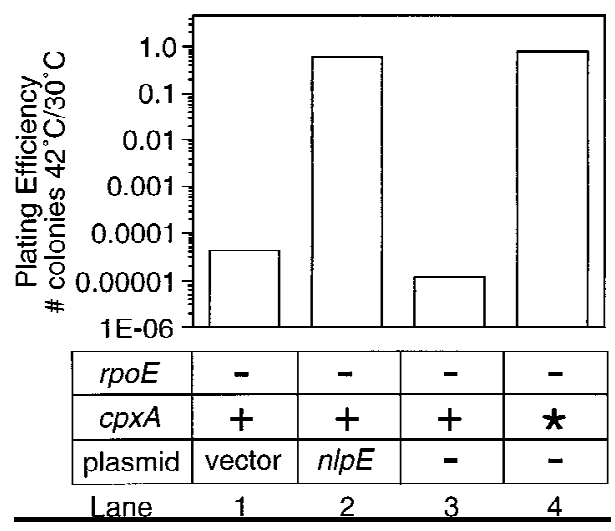

Figure 2. Plating efficiency of $\mathrm{rpoE}:: \Omega \mathrm{Cm}$ cells activated for the $C p x$ pathway. The efficiency of plating of rpoE:: $\Omega \mathrm{Cm}$ cells containing vector al one (lane 1) or pBA25 (lane 2), or no plasmid and a wild-type (lane 3 ) or constitutively activated (lane 4) cpxA allele was determined as described in Materials and M ethods. The numerical values of the plating efficiency of each strain were vector alone, $4.2 \times 10^{-5}$; $\mathrm{pBA} 25,0.6$; $\mathrm{cpxA}^{+}, 1.1 \times 10^{-5}$; срхA*, 0.8 .

high temperature (Fig. 3, lanes 2,4). In addition, the plating efficiency of $\mathrm{rpoE}^{-}$degP- double mutant strains was not restored by overexpression of $\mathrm{N} / \mathrm{pE}$, as double mutant cells containing vector alone or a plasmid overexpressing $\mathrm{N}$ IpE plated with virtually the same efficiency $\left(<1.8 \times 10^{-7}\right.$ vs. $\left.<5.0 \times 10^{-7}\right)$. These results indicate that degP is an essential component of suppression of the $\mathrm{rpoE}^{-}$temperature-sensitive phenotype by the $\mathrm{C} p \mathrm{x}$ pathway.

To determine whether overexpression or restoration of

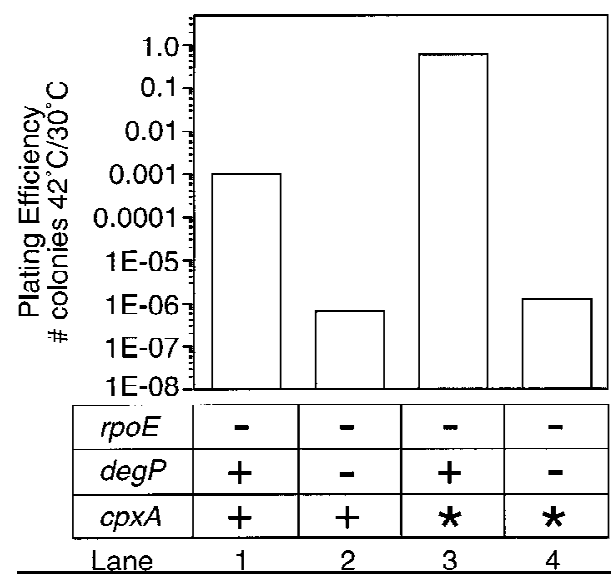

Figure 3. Plating efficiency of $\mathrm{rpoE}:: \Omega \mathrm{Cm}$ cells lacking degP. The plating efficiency of rpoE:: $\Omega \mathrm{Cm} \mathrm{cpxA}^{+}($lane 1$), \mathrm{rpoE}:: \Omega \mathrm{Cm}$ сpxA ${ }^{+}$degP::Km (lane 2), rpoE:: $\Omega \mathrm{Cm}$ cpxA* (lane 3), and rpoE:: $\Omega \mathrm{Cm}$ сpxA* degP::Km (lane 4 ) strains was determined as described in $M$ aterials and $M$ ethods. The numerical values of each plating efficiency were $\mathrm{rpoE}:: \Omega \mathrm{Cm} \mathrm{cpxA}^{+}, 1.0 \times 10^{-3}$; rpoE:: $\Omega \mathrm{Cm}$ сpxA ${ }^{+}$degP::Km, $6.7 \times 10^{-7}$; rpoE:: $\Omega \mathrm{Cm}$ cpxA*, 0.6; and rpoE:: $\Omega \mathrm{Cm}$ cpxA* degP::Km, $1.2 \times 10^{-6}$. Note that all strains used in this experiment were recA ${ }^{+}$.
degP expression was sufficient to rescue $\mathrm{rpoE}^{-}$cells, we introduce a plasmid encoding degP into the original $\mathrm{rpoE}^{-}$strain. Introduction of the degP plasmid partially restores growth at high temperature to $\mathrm{rpoE}^{-}$cells, as cells containing this plasmid exhibit a $10^{3}$-fold higher plating efficiency than a similar strain containing vector al one (Fig. 4a, lanes 2,1). However, degP did not restore plating efficiency to the same extent as full activation of the $C$ px pathway (Fig. 4a, lanes 2,4).

To ensure that degP expression in cells carrying the plasmid was at least as high as cells fully suppressed by activation of the Cpx pathway, Western blot analysis of DegP expression was carried out (Fig. 4b). The steadystate level of DegP in cells grown at $30^{\circ} \mathrm{C}$ or $42^{\circ} \mathrm{C}$ was determined, and these studies revealed that $\mathrm{rpoE}^{-}$cells containing the degP plasmid (Fig. 4b, lanes 4,9) expressed
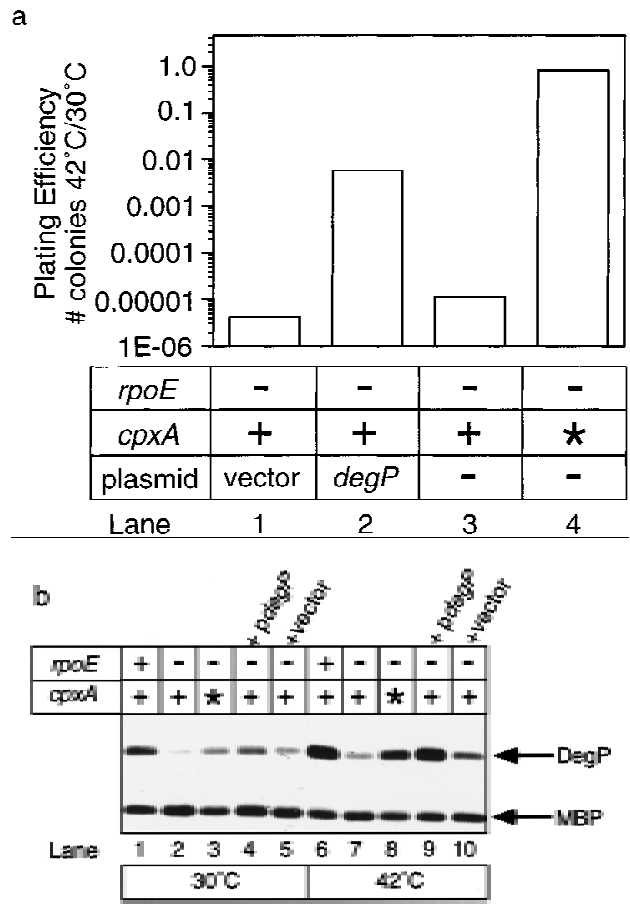

Figure 4. Phenotype of $r p o E:: \Omega \mathrm{Cm}$ cells overexpressing DegP. (a) Plating efficiency. The efficiency of plating at $42^{\circ} \mathrm{C}$ of rpoE:: $\Omega \mathrm{Cm}$ cells containing vector al one (lane 1 ) or a plasmid overexpressing degP (lane 2) was determined. For comparison, the plating efficiencies of $\mathrm{rpoE}^{-}$cells containing a wild-type (lane 3 ) or fully activated (lane 4) cpxA allele are also shown. The numerical values of each plating efficiency were vector alone, $4.1 \times 10^{-6}$; pdegP, $6.0 \times 10^{-3} ; \mathrm{cpxA}^{+}, 1.1 \times 10^{-5}$; and cpxA*, 0.8. (b) Western blot analysis of DegP expression. Wildtype cells (lanes 1,6), rpoE:: $\Omega \mathrm{Cm}$ cells containing wild-type (cpxA ${ }^{+}$, lanes 2,7 ) or activated (cpxA*, Ianes 3,8 ) cpxA alleles, or $\mathrm{rpoE}:: \Omega \mathrm{Cm}$ cells containing either a plasmid overexpressing degP (pdegP, lanes 4,9 ) or vector al one (lanes 5,10 ) were grown at $30^{\circ} \mathrm{C}$ to mid-log phase and then shifted to $42^{\circ} \mathrm{C}$ and grown for 20 min. The steady-state level of DegP expression in cells grown before and after heat shock was then determined by Western blot analysis as described in M aterials and M ethods. As a loading control, the blot was also probed with antibodies against maltose-binding protein (M BP). 
at least as much, if not more, DegP as cells carrying the cpxA* allele (Fig. 4b, lanes 3,8) at both temperatures. Together, these analyses show that overexpression of DegP al one does not restore growth to the same level s as does activation of the $\mathrm{Cpx}$ pathway, indi cating that other Cpx-controlled genes are required for full suppression of the $\mathrm{rpoE}^{-}$temperature-sensitive defect.

\section{Discussion}

The activity of the alternate $\sigma$-factor $\sigma^{\mathrm{E}}$ of $\mathrm{E}$. coli is induced by several stressors, including elevated temperature, ethanol, and alterations in the expression and maturation of OMPs, which lead to the periplasmic accumulation of misfolded or unfolded protein species (Erickson et al. 1987; Erickson and Gross 1989; Raina et al. 1995; Rouvière et al. 1995; M issiakas et al. 1996; Rouvière and Gross 1996). The $\sigma^{\mathrm{E}}$ regulon includes several genes whose products are likely to be required for envelope integrity because cells lacking $\sigma^{\mathrm{E}}$ are sensitive to several conditions that potentially disrupt outer membrane function (Hiratsu et al. 1995; Raina et al. 1995; Rouvière et al. 1995). Here we show that activation of a second signal transduction cascade, the Cpx pathway, can restore viability to $\mathrm{rpoE}^{-}$cells at elevated temperature. Suppression of the temperature-sensitive phenotype requires the expression of at least two Cpx-dependent genes, one of which encodes for the periplasmic protease DegP, whose expression is also under $\sigma^{\mathrm{E}}$ control. These results suggest that E. coli has at least two partially overlapping signal transduction cascades capable of relieving extracytoplasmic stress.

\section{Cellular role of the Cpx pathway}

Although the cpx genes were first identified over a decade ago (M cEwen and Silverman 1980a), a clear-cut role for the Cpx pathway in E. coli physiology has proven more elusive. The Cpx pathway has been described in relation to pleiotropic phenotypes, including defective conjugative plasmid transfer (McEwen and Silverman 1980a,b), low level resistance to aminoglycoside antibiotics (Thorbjarnardottir et al. 1978), and al terations in the protein composition of the outer membrane (McEwen and Silverman 1982; McEwen et al. 1983), that result from constitutive activation of this pathway. It is unclear whether these phenotypes reflect the normal function of the Cpx pathway or result from aberrant activation (Danese et al. 1995). In addition, cells lacking the Cpx pathway show no obvious phenotypes (Danese et al. 1995; L. Connolly, unpubl.).

The observation that the Cpx pathway modulates expression of the periplasmic protease DegP (Danese et al . 1995) led to the idea that this pathway is involved in combating extracytopl asmic stress, and activation of the Cpx pathway by either mutational induction or overexpression of $\mathrm{N} / \mathrm{pE}$ has been shown to relieve the toxicity of several periplasmic LamB mutant proteins (Cosma et al. 1995; Snyder et al. 1995). The recent finding that the Cpx pathway modulates the expression of other peri plas- mic proteins involved in folding supports the idea that this pathway is involved in regulating protein folding and turnover in the extracytopl asmic compartment (Danese and Silhavy 1997; Pogliano et al. 1997).

\section{What does the Cpx pathway sense?}

The ability of the $C p x$ pathway to relieve extracytoplasmic stress due to protein misfolding has been described only in relation to mutational activation of this pathway (Cosma et al. 1995) or activation by $\mathrm{nlpE}$ in multicopy (Snyder et al. 1995), suggesting that CpxA may not directly sense the folding state of this compartment. The mechanism of induction by overexpression of $\mathrm{N} / \mathrm{pE}$ remains unclear. Overexpression of several other lipoproteins did not activate the Cpx pathway (Danese et al. 1995), indicating that N IpE is a specific activator. In addition, the fast kinetics of activation by $\mathrm{N}$ IpE (Pogliano et al . 1997) suggest that this activator acts directly on the Cpx pathway and not through slowly altering some physical or biochemical property of the envelope. N IpE has a putative serine protease inhibitor motif, and it has been proposed that N IpE may modulate or monitor protease activity in periplasm (Snyder et al. 1995). For instance, NIpE may use the serine protease inhibitor to monitor free levels of DegP activity in the periplasm. U pon an increase in substrates, DegP may be titrated off of $\mathrm{N} / \mathrm{pE}$, and an increase in the levels of free $\mathrm{N}$ IpE may signal the need for increased transcription of degP to the Cpx pathway.

In this regard, it is interesting to note that the temperature-sensitive phenotype of cells lacking degP can be suppressed by null mutations in the gene encoding a second envel ope-associated protease, OmpT (N. M cFarland, unpubl.). An imbalance in the protease activities of the envelope may lead to a similar imbalance of key substrates, which in turn might alter envelope physiology. For example, if OmpT were a substrate of DegP, then deletion of DegP would lead to an increase in OmpT activity and a subsequent decrease in OmpT substrates. It has been proposed that several of the phenotypes of cells containing constitutive al leles of cpxA result from such an imbalance of proteolytic activity that leads to alterations in the protein composition of the outer membrane (Danese et al. 1995).

The C px pathway has al so been shown to be required for the $\mathrm{pH}$-dependent activation of the Shigella sonnei virF gene (Nakayama and Watanabe 1995), which encodes a positive regulator of the i paBCD invasion genes. This observation suggests that the $C p x$ system may be responsive to changes in $\mathrm{pH}$ and play a role in bacterial pathogenesis. It will be interesting to determine whether known Cpx-dependent genes are also modulated in re sponse to $\mathrm{pH}$ alterations and whether any of these genes encode functions required for survival under such conditions.

Finally, the Cpx pathway is activated in cells lacking phosphatidyl-ethanol amine (M ilekovskaya and Dowhan 1997), suggesting that this pathway may al so sense al- 
terations in the structural or physical integrity of the cell envelope. Deletion of $\mathrm{nlpE}$ from these strains did not alter $\mathrm{Cpx}$ activation, suggesting that the $\mathrm{Cpx}$ pathway may directly sense these envelope changes (Milekovskaya and Dowhan 1997). It remains to be seen whether each of the conditions described above generates a single, common signal that is sensed by CpxA or whether this pathway is capable of responding to diverse signals.

What is the relationship between the $\mathrm{Cpx}$ and $\sigma^{\mathrm{E}}$ pathways?

Several lines of evidence suggest that the $C p x$ and $\sigma^{E}$ pathways represent distinct stress-response systems that do not sense or regulate redundant functions (Fig. 5). Deletion of either the $C p x$ pathway or $\mathrm{nlpE}$ leads to no obvious phenotype (Danese et al. 1995; Snyder et al. 1995; L. Connolly, unpubl.), suggesting that this pathway may contribute to envelope homeostasis under a specific set of conditions not normally achieved in the laboratory or that Cpx-controlled genes exhibit a basal level of transcription that is sufficient for cell growth. In contrast, the $\sigma^{\mathrm{E}}$ pathway appears to be invol ved in envelope homeostasis under most growth conditions. Cells lacking $\sigma^{\mathrm{E}}$ are sensitive to membrane-disrupting agents and fail to grow at high temperature (Hiratsu et al. 1995; Raina et al. 1995; Rouvière et al. 1995). Recent work suggests that $\sigma^{\mathrm{E}}$-directed functions are required at all temperatures, as we have discovered that our strains lacking $\sigma^{\mathrm{E}}$ contain an unidentified suppressor that is required for low temperature growth (A. De Las Peñas, L. Connolly, and C.A. Gross, in prep.). The presence of a
cpxA* allele does not alleviate the requirement for this suppressor (L. Connolly, unpubl.), indicating that the $\mathrm{C} p x$ pathway cannot substitute for $\sigma^{\mathrm{E}}$ under all conditions. In addition, the suppressor al one does not confer a temperature-sensitive phenotype (L. Connolly, unpubl.), indicating that the temperature-sensitive phenotype observed in $\mathrm{rpoE}^{-}$strains is attributable to a loss of $\sigma^{\mathrm{E}}$ dependent gene products. Activation of the $C$ px pathway compensates for this loss of $\sigma^{\mathrm{E}}$-dependent gene expression normally requi red at high temperature, as evidenced by the observation that restoration of expression of a single $\sigma^{\mathrm{E}}$-dependent gene product, DegP, by activation of the $C p x$ pathway accounts for the majority of suppression (Fig. 4a).

In addition to exhi biting distinct phenotypes, each system appears to respond to different signals. Overexpression of N IpE does not induce $\sigma^{\mathrm{E}}$ activity in general, as measured from a minimal $\sigma^{\mathrm{E}}$-dependent promoter (Danese et al. 1995), and several types of stressors that induce $\sigma^{\mathrm{E}}$ activity do not induce the Cpx pathway (Danese et al . 1995). For example, alterations in the maturation of OMPs, either by overexpression or the titration or periplasmic folding agents, uniquely induce $\sigma^{\mathrm{E}}$ (M ecsas et al. 1993; Danese et al. 1995; Missiakas et al. 1996; Rouvière and Gross 1996). Alterations in the lipid composition of the envelope have been shown recently to induce the Cpx pathway (Milekovskaya and Dowhan 1997), and it remains to be seen whether these conditions similarly alter $\sigma^{\mathrm{E}}$ activity.

The $\mathrm{Cpx}$ and $\sigma^{\mathrm{E}}$ regulons overlap at degP; however, several observations suggest that the two regulons are not identical . First, the Cpx system does not rely exclusively on holoenzyme containing $\sigma^{\mathrm{E}}$ for transcriptional activation. Although $\mathrm{CpxR}$ and $\sigma^{\mathrm{E}}$ appear to act together

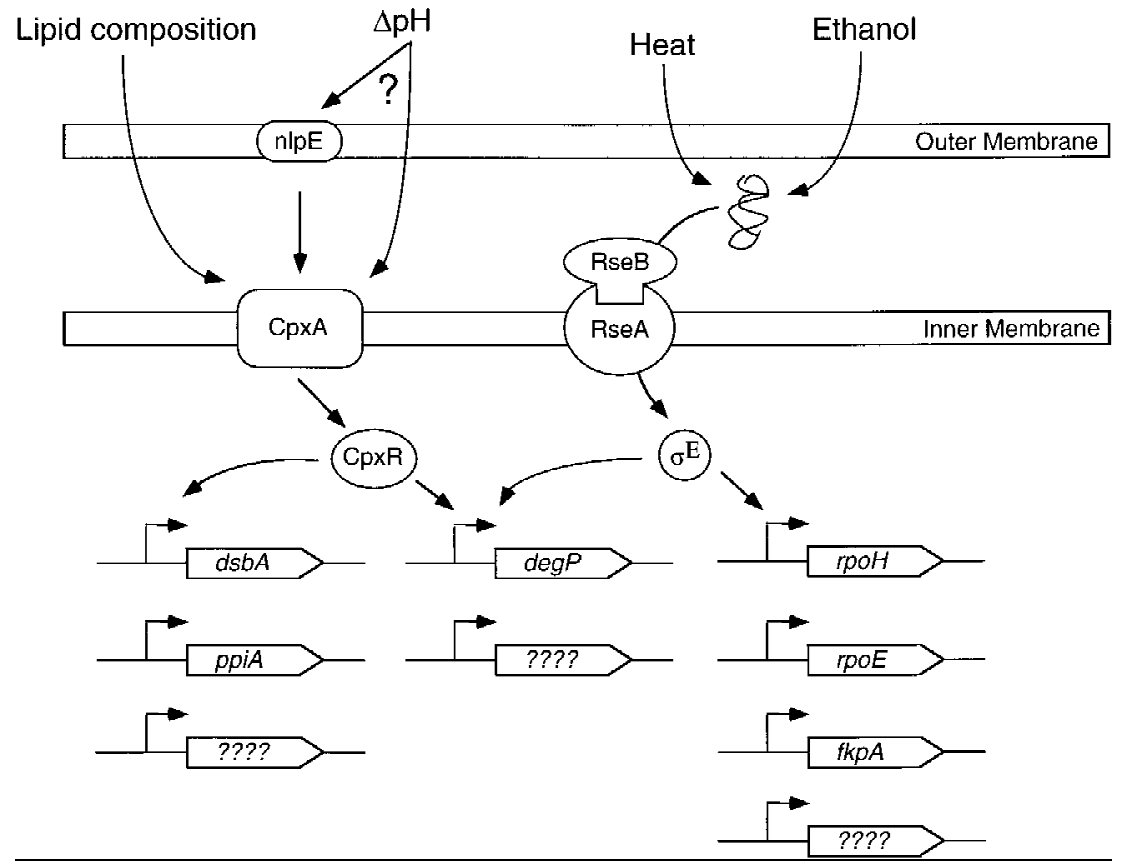

Figure 5. The extracytoplasmic stress response is controlled by partially overlapping pathways. The Cpx pathway controls the expression of several resident periplasmic folding proteins (DegP, PpiA, and DsbA) in response to overproduction of the outer membrane lipoprotein NIpE, and perhaps structural or physical alterations in the envelope induced by changes in $\mathrm{pH}$ or lipid composition. The al ternate $\sigma$-factor $\sigma^{\mathrm{E}}$ controls the expression of degP, rpoH, rpoE, $\mathrm{fkpA}$, and several other unidentified genes in response to the accumulation of misfolded OMP precursors in the periplasmic space. (See Discussion for further details). 
at the degP promoter, C pxR is capable of inducing degP transcription approximately threefold in the absence of $\sigma^{\mathrm{E}}$ (Danese et al . 1995). In addition, new members unique to either the $\mathrm{Cpx}$ or $\sigma^{\mathrm{E}}$ regulons have been described (Fig. 5) (Danese and Silhavy 1997; Pogliano et al. 1997). The $\mathrm{Cpx}$ proteins regulate expression of the disulfide bond isomerase dsbA (Danese and Silhavy 1997; Pogliano et al. 1997), and the peptidyl prolyl isomerase (PPlase), ppiA (Pogliano et al. 1997), whereas $\sigma^{\mathrm{E}}$ induces the expression of a second PPlase, FkpA (Danese and Silhavy 1997). Although each regulon encodes similar biochemical activities, and activation of the $C p x$ pathway can rescue the temperature-sensitive defect of $\mathrm{rpoE}^{-}$cells, activation of the $\sigma^{\mathrm{E}}$ pathway cannot substitute for the Cpx system under some conditions. For example, activation of $\sigma^{\mathrm{E}}$ by overexpression of OM Ps does not relieve the toxicity of LamB mutant proteins (Snyder et al . 1995). These results suggest that the two pathways can be induced independently in response to uni que stressors and that they may integrate these disparate signals arising in the face of multifaceted insults. A complete understanding of the relationship between these two systems awaits further molecular characterization of their regulon members and inducing signals.

\section{Regulation of DegP}

From these experiments and those of others, it is clear that DegP plays a key role in combating envel ope stress (Lipinska et al. 1989; Strauch et al. 1989; Cosma et al. 1995; Snyder et al. 1995). During the original characterization of the degP promoter, it became evident that degP was a heat shock gene (Lipinska et al. 1988). This heat induction appeared to be independent of the main heat shock $\sigma$-factor, $\sigma^{32}$, and was instead found to depend on a second heat shock $\sigma, \sigma^{\mathrm{E}}$ (Lipinska et al. 1988; Erickson and Gross 1989). These experiments provided some of the first evidence that $\sigma^{\mathrm{E}}$ controlled a second heat shock regul on. However, it became clear during the course of our experiments that the expression of DegP is still induced by heat shock in the absence of $\sigma^{\mathrm{E}}$ (Fig. $4 \mathrm{~b}$ ). The heat shock regulation of degP has been shown recently to be independent of the Cpx pathway in cells containing $\sigma^{E}$ (Pogliano et al. 1997), and we have observed heat shock induction of DegP in cells lacking both of these systems (L. Connolly, unpubl.). These results raise the possi bility that a third regulatory cascade modulates DegP expression and help to explain the seemingly contradictory observation that cells lacking $\sigma^{\mathrm{E}}$ and, by extension the entire $\sigma^{\mathrm{E}}$ regul on, plate 100-fold better than cells lacking DegP al one $\left(10^{-3}\right.$ vs. $10^{-5}$; L. Connolly, unpubl.). It is al so clear that this residual expression contributes substantially to the survival of $\mathrm{rpoE}^{-}$cells at high temperature (Fig. 3), underscoring the key role that DegP plays in maintaining envelope integrity. From these experiments, it is unclear at what level this $\sigma^{\mathrm{E}}$-independent induction of DegP is occurring, and it will be interesting to determine how DegP levels are regulated in the absence of the $\sigma^{\mathrm{E}}$ and $\mathrm{Cpx}$ systems.

\section{Materials and methods}

Media, reagents, and enzymes

Luria-Bertani (LB) and M 9 minimal media were prepared as described (Sambrook et al. 1989). Where needed, media were supplemented with $100 \mu \mathrm{g} / \mathrm{ml}$ of ampicillin (Ap100), $3 \mu \mathrm{g} / \mathrm{ml}$ of amikacin, $50 \mu \mathrm{g} / \mathrm{ml}$ of spectinomycin (Sp50), $10 \mu \mathrm{g} / \mathrm{ml}$ of tetracycline (Tc10), $30 \mu \mathrm{g} / \mathrm{ml}$ kanamycin $(\mathrm{Km} 30), 12 \mu \mathrm{g} / \mathrm{ml}$ of chloramphenicol (Cm12), or $0.4 \%$ glucose.

\section{Strains}

Bacterial strains used in this study are described in Table 2.

\section{Plasmids}

Plasmids used in this study are listed in Table 2. The E. coli genomic library was a generous gift of Alan Derman (University of California, San Francisco) and contains Pstl-digested chromosomal DNA from MG1655 cloned into the Pstl site of pUC19 (N orrander et al. 1983) as described (N eumann et al. 1992). pBA 25 was isolated di rectly from this library. During the course of subcloning $\mathrm{nl} \mathrm{pE}$ from this plasmid, we noticed a difference in a single restriction site versus a previously reported sequence derived from MC4100 (Snyder et al. 1995), suggesting that sequence heterogeneity of this gene may exist among different $\mathrm{E}$. coli isolates. pBA26 was constructed by deleting a 2.1-kb AfIIIXbal fragment from pBA25. pLC224 was constructed by PCR amplification of nlpE from pBA25 using primers NLPE28 (5'CAGCGGTCGGGAATTCAAAGAAGGAATG) and NLPE29 (5'-GGGGGGAAGCTTACGCCTTATCCGGCCTAC). The resulting product was then cloned into the EcoRI-HindlII sites of pLC222 [an Ap ${ }^{R}$ version of pSU 18 (Bartolomé et al. 1991), containing the bla gene from pBS SK + cloned into the Sspl sites of pSU 18]. pAP87 was constructed by subcloning a 3.0-kb DralBamHI fragment from pKS17 into pACYC177 (Rose 1988).

\section{DNA sequencing}

Sequence was obtained from either end of the insert in pBA25 using vector-derived primers ( $M 13$ Sequencing Primer and M 13 Reverse Sequencing Primer) and a cycle sequencing kit according to the manufacturer's directions (GIBCO BRL, Gaithersburg, MD).

\section{Plating efficiencies}

recA56 versions of all strains were used to determine plating efficiencies, with the exception of the data in Fig. 3 (CAG22216, CAG33104, CAG33067, CAG33245).

Tenfold dilutions of the desired strain were made in $1 \mathrm{ml}$ of LB from fresh overnight cultures grown at $30^{\circ} \mathrm{C}$ in LB plus the appropriate antibiotic and $0.4 \%$ glucose for $\mathrm{rpoE}:: \Omega \mathrm{Cm}$ $\mathrm{cpxR}:: \Omega$ Sp strains containing the following plasmids: pUC18, pBA 25, pLC222, and pLC224. Each dilution $(100 \mu \mathrm{l})$ was plated in duplicate on LB or A 100 for plasmid-containing strains. One plate was incubated at $30^{\circ} \mathrm{C}$, the other at $42^{\circ} \mathrm{C}$ for $24-48 \mathrm{hr}$, and the resulting number of colonies counted. Plating efficiency was scored as the number of colonies arising at $42^{\circ} \mathrm{C}$ divided by the number at $30^{\circ} \mathrm{C}$, and the values reported represent the average of at least three independent determinations.

Detection of DegP and maltose-binding protein by Western blot

Fifteen milliliters of LB were inoculated with $150 \mu$ l of a fresh overnight culture of the desired strains. Cells were grown at 
Table 2. Strains and plasmids used in this study

\begin{tabular}{|c|c|c|}
\hline & Rel evant genotype & Reference \\
\hline \multicolumn{3}{|l|}{ Strain } \\
\hline CAG16037 & MC1061 $\phi(\lambda$ rpoH P3::IacZ) & M ecsas et al. (1993) \\
\hline CAG37193 & CAG16037 srl-300::Tn10 recA56 & this work \\
\hline CAG22216 & CAG16037 rpoE:: $\Omega \mathrm{Cm}$ & Rouvière et al. (1995) \\
\hline CAG22700 & CAG22216 srl-300::Tn10 recA56 & this work \\
\hline CAG33126 & CAG22700, pUC18 & this work \\
\hline CAG33127 & CAG22700, pBA25 & this work \\
\hline CAG33183 & CAG22700, pBA26 & this work \\
\hline CAG33267 & CAG22700, pBR322 & this work \\
\hline CAG33268 & CAG22700, pLD404 & this work \\
\hline CAG33190 & CAG22700, pLC222 & this work \\
\hline CAG33191 & CAG22700, pLC224 & this work \\
\hline CAG 33113 & CAG22700, pAP87 & this work \\
\hline CAG33114 & CAG22700, pACYC177 & this work \\
\hline PND325 & 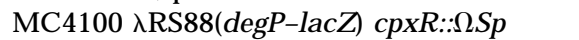 & Danese et al. (1995) \\
\hline CAG18636 & MG1655 zii-3088::Tn10Km & Singer et al. (1989) \\
\hline CAG33064 & PND 325 zii-3088::Tn10Km & this work \\
\hline CAG33069 & 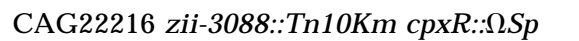 & this work \\
\hline CAG33091 & CAG33069 srl-300::Tn10 recA56 & this work \\
\hline CAG33239 & CAG33091, pUC18 & this work \\
\hline CAG33240 & CAG33091, pBA25 & this work \\
\hline CAG33241 & CAG33091, pLC222 & this work \\
\hline CAG33242 & CAG33091, pLC224 & this work \\
\hline CAG16237 & CAG16037 degP::Km & M ecsas et al. (1993) \\
\hline CAG33245 & CAG33104 degP::Km & this work \\
\hline CAG33067 & CAG22216 degP::Km & this work \\
\hline CAG33070 & CAG33067 srl-300::Tn10 recA56 & this work \\
\hline CAG33163 & CAG33070, pUC18 & this work \\
\hline CAG33164 & CAG33070, pBA 25 & this work \\
\hline CLC145 & MC4100 cpx103 IamBA23D & Cosma et al. (1995) \\
\hline CAG33104 & CAG22216 cpx103 & this work \\
\hline CAG33131 & CAG33104 srl-300::Tn10 recA56 & this work \\
\hline \multicolumn{3}{|l|}{ Plasmid } \\
\hline pUC18 & cloning vector, ColE1 ori, Ap & N orrander et al. (1983) \\
\hline pBA25 & yaej, nlpE, yaeF, drpA/pros in pUC, Ap & this work \\
\hline pBA26 & yaej and nlpE in pUC, Ap & this work \\
\hline pSU 18 & cloning vector, p15A ori, $\mathrm{Cm}$ & Bartolomé et al. (1991) \\
\hline pLC222 & bla gene from pUC cloned into pSU 18, Ap & this work \\
\hline pLC224 & $\mathrm{nlpE}$ in $\mathrm{pLC} 2222, \mathrm{Ap}$ & this work \\
\hline pBR322 & cloning vector, ColEl ori, Ap, Tc & Bolivar et al. (1977) \\
\hline pLD404 & yae, nlpE, and yaeF in pBR322 & Snyder et al. (1995) \\
\hline pACYC177 & cloning vector, p15A ori, $\mathrm{Km}, \mathrm{Ap}$ & Rose (1988) \\
\hline pAP87 & degP in $\mathrm{PACY} C 177, \mathrm{Km}$ & this work \\
\hline
\end{tabular}

$30^{\circ} \mathrm{C}$ to an $\mathrm{OD}_{600}$ of 0.5 , and $0.9 \mathrm{ml}$ of culture was sampled directly into $0.1 \mathrm{ml}$ of $50 \%$ TCA on ice, vortexed, and placed at $-20^{\circ} \mathrm{C}$ overnight. The remainder of the culture was shifted to $42^{\circ} \mathrm{C}$, and grown for $20 \mathrm{~min}$. After $20 \mathrm{~min}$ of growth, the $O D_{600}$ of the culture was determined and $0.9 \mathrm{ml}$ sampled directly into TCA as above. The next day, TCA precipitates were pelleted at $17,500 \mathrm{~g}$ for $30 \mathrm{~min}$ at $4^{\circ} \mathrm{C}$. The pellets were washed twice with $100 \%$ acetone, air-dried, and resuspended in $1 \times$ protein sample buffer (50 mm Tris-Cl at pH 6.8, $100 \mathrm{~mm}$ DTT, 2\% SDS, $0.2 \%$ bromophenol blue) to a concentration of $10^{7}$ cells $/ \mu$ l. Cells $\left(2.5 \times 10^{7}\right)$ were run on $10 \%$ SDS-polyacrylamide gels and transferred to a nitrocellulose membrane. The membrane was blocked overnight at room temperature with 3\% nonfat dry milk in TBST (10 mm Tris at pH 8.0, $150 \mathrm{~mm} \mathrm{NaCl}, 0.2 \%$ Tween 20). A mixture of anti-DegP and maltose-binding protein (M BP) primary antibodies (provided by Jon Beckwith, Harvard M edical
School, Boston, MA) were used at 1:10,000 concentration in TBST plus $1 \%$ milk for $1 \mathrm{hr}$ at room temperature. The blot was washed three times for 5 min each with TBST, then incubated with 1:10,000 dilution of sheep anti-rabbit peroxidase (Boehringer $\mathrm{M}$ annheim, Indianapolis, IN ) for $1 \mathrm{hr}$ at room temperature, and washed again as before. It was then developed with enhanced chemiluminescence (ECL) reagents (Amersham, Arlington Heights, IL) and Hyperfilm ECL (Amersham, Arlington Heights, IL) and exposed to film from 5-30 sec.

\section{Acknowledgments}

We give special thanks to Chris Cosma for sharing strains. We al so thank Paul Danese and Tom Silhavy for strains and hel pful discussions concerning this manuscript, Alan Derman for the 
gift of the genomic library, and Joe Pogliano, Jon Beckwith, Paul Danese, and Tom Silhavy for sharing results prior to publication. We also thank Christophe Herman for critical reading of this manuscript. This work was supported by U.S. Public Service grant GM 36278 from the National Institutes of Health. L.C. was al so supported by the U CSF M edical Scientist Training Program GM 07618.

The publication costs of this article were defrayed in part by payment of page charges. This article must therefore be hereby marked "advertisement" in accordance with 18 USC section 1734 solely to indicate this fact.

\section{References}

Altschul, S.F., W. Gish, W. Miller, E.W. Myers, and D.J. Lipman. 1990. Basic local alignment search tool. J. Mol. Biol. 215: 403-410.

Bartolomé, B., Y. Jubete, E. Martinez, and F. de la Cruz. 1991. Construction and properties of a family of pACYC184-derived cloning vectors compatible with pBR322 and its de rivatives. Gene 102: 75-78.

Becker, J. and E.A. Craig. 1994. Heat-shock proteins as molecuIar chaperones. Eur. J. Biochem. 219: 11-23.

Bolivar, F., R.L. Rodriguez, P.J. Greene, M.C. Betlach, H.L. Heyneker, and H.W. Boyer. 1977. Construction and characterization of new cloning vehicles. II. A multipurpose cloning system. Gene 2: 95-113.

Bukau, B. 1993. Regulation of the Escherichia coli heat-shock response. Mol. Microbiol. 9: 671-680.

Cosma, C.L., P.N. Danese, J.H. Carlson, T.J. Silhavy, and W.B. Snyder. 1995. Mutational activation of the Cpx signal transduction pathway of Escherichia coli suppresses the toxicity conferred by certain envelope-associated stresses. Mol. Microbiol. 18: 491-505.

Cox, J.S. and P. Walter. 1996. A novel mechanism for regulating activity of a transcription factor that controls the unfolded protein response. Cell 87: 391-404.

Cox, J.S., C.E. Shamu, and P. Walter. 1993. Transcriptional induction of genes encoding endoplasmic reticulum resident proteins requires a transmembrane protein kinase. Cell 73: 1197-1206.

Danese, P. and T. Silhavy. 1997. The $\sigma^{\mathrm{E}}$ and Cpx signal transduction systems control the synthesis of periplasmic protein-folding enzymes in Escherichia coli. Genes \& Dev. 11: 1183-1193.

Danese, P.N., W.B. Snyder, C.L. Cosma, L.J. Davis, and T.J. Silhavy. 1995. The Cpx two-component signal transduction pathway of Escherichia coli regulates transcription of the gene specifying the stress-inducible periplasmic protease, DegP. Genes \& Dev. 9: 387-398.

De Las Peñas, A., L. Connolly, and C.A. Gross. 1997. The $\sigma^{E_{-}}$ mediated response to extracytoplasmic stress in Escherichia coli is transduced by RseA and RseB, two negative regulators of $\sigma^{\mathrm{E}}$. Mol. Microbiol. 24: 373-386.

Erickson, J.W. and C.A. Gross. 1989. Identification of the $\sigma^{\mathrm{E}}$ subunit of Escherichia coli RNA polymerase: A second alternate $\sigma$ factor involved in high-temperature gene expression. Genes \& Dev. 3: 1462-1471.

Erickson, J.W., V. Vaughn, W.A. Walter, F.C. Neidhardt, and C.A. Gross. 1987. Regulation of the promoters and transcripts of $\mathrm{rpoH}$, the Escherichia coli heat shock regulatory gene. Genes \& Dev. 1: 419-432.

Gamer, J., H. Bujard, and B. Bukau. 1992. Physical interaction between heat shock proteins DnaK, Dnal, and GrpE and the bacterial heat shock transcription factor $\sigma^{32}$. Cell 69: 833842.
Gamer, J., G. M ulthaup, T. Tomoyasu, J.S. M cCarty, S. Rudiger, H.J. Schonfeld, C. Schirra, H. Bujard, and B. Bukau. 1996. A cycle of binding and release of the DnaK, Dnal, and GrpE chaperones regulates activity of the Escherichia coli heat shock transcription factor $\sigma^{32}$. EMBO J. 15: 607-617.

Georgopoulos, C., K. Liberek, M. Zylicz, and D. Ang. 1994. Properties of the heat shock proteins of Escherichia coli and the autoregulation of the heat shock response. In The biology of heat shock proteins and molecular chaperones (ed. R.I. M orimoto, A. Tissieres, and C. Georgopoulos), pp. 209249. Cold Spring Harbor Laboratory Press, Cold Spring Harbor, NY.

Gross, C.A. 1996. Function and regulation of the heat shock proteins. In Escherichia coli and Salmonella typhimurium. Cellular and molecular biology, 2nd ed. (ed. R. Curtiss et al.) pp. 1382-1399. ASM Press, Washington, D.C.

Grossman, A.D., J.W. Erickson, and C.A. Gross. 1984. The htpR gene product of $\mathrm{E}$. coli is a $\sigma$ factor for heat-shock promoters. Cell 38: 383-390.

Gupta, S.D., B.T. Lee, J. Camakaris, and H.C. Wu. 1995. Identification of cutC and cutF (nlpE) genes involved in copper tolerance in Escherichia coli. J. Bacteriol. 177: 4207-4215.

Hiratsu, K., M. Amemura, H. N ashimoto, H. Shinagawa, and K. Makino. 1995. The rpoE gene of Escherichia coli, which encodes $\sigma^{\mathrm{E}}$, is essential for bacterial growth at high temperature. J. Bacteriol. 177: 2918-2922.

Landick, R., V. Vaughn, E.T. Lau, R.A. VanBogelen, J.W. Erickson, and F.C. N eidhardt. 1984. N ucl eotide sequence of the heat shock regulatory gene of $\mathrm{E}$. coli suggests its protein product may be a transcription factor. Cell 38: 175-182.

Liberek, K. and C. Georgopoulos. 1993. Autoregulation of the Escherichia coli heat shock response by the DnaK and DnaJ heat shock proteins. Proc. Natl. Acad. Sci. 90: 11019-11023.

Liberek, K., T.P. Galitski, M. Zylicz, and C. Georgopoulos. 1992. The DnaK chaperone modulates the heat shock response of Escherichia coli by binding to the $\sigma^{32}$ transcription factor. Proc. Natl. Acad. Sci. 89: 3516-3520.

Lipinska, B., S. Sharma, and C. Georgopoulos. 1988. Sequence analysis and regulation of the htrA gene of Escherichia coli: a $\sigma^{32}$-independent mechanism of heat-inducible transcription. Nucleic Acids Res. 16: 10053-10067.

Lipinska, B., O. Fayet, L. Baird, and C. Georgopoulos. 1989. Identification, characterization, and mapping of the Escherichia coli htrA gene, whose product is essential for bacterial growth only at elevated temperatures. J. Bacteriol. 171: 1574-1584.

McEwen, J. and P. Silverman. 1980a. Chromosomal mutations of Escherichia coli that alter expression of conjugative plasmid functions. Proc. Natl. Acad. Sci. 77: 513-517.

-_- 1980b. Genetic analysis of Escherichia coli K-12 chromosomal mutants defective in expression of F-plasmid functions: Identification of genes cpxA and cpxB. J. Bacteriol. 144: $60-67$.

-_- 1982. Mutations in genes cpxA and cpxB alter the protein composition of Escherichia coli inner and outer membranes. J. Bacteriol. 151: 1553-1559.

M cEwen, J., L. Sambucetti, and P.M. Si lverman. 1983. Synthesis of outer membrane proteins in cpxA cpxB mutants of Escherichia coli K-12. J. Bacteriol. 154: 375-382.

McMillan, D.R., M.J. Gething, and J. Sambrook. 1994. The celIular response to unfol ded proteins: Intercompartmental signaling. Curr. O pin. Biotechnol. 5: 540-545.

Mecsas, J., P.E. Rouvière, J.W. Erickson, T.J. Donohue, and C.A. Gross. 1993. The activity of $\sigma^{\mathrm{E}}$, an Escherichia coli heatinducible sigma-factor, is modulated by expression of outer membrane proteins. Genes \& Dev. 7: 2618-2628. 
Milekovskaya, E. and W. Dowhan. 1997. The Cpx two-component signal transduction pathway is activated in Escherichia coli mutant strains lacking phosphatidylethanolamine. J. Bacteriol. 179: 1029-1034.

Missiakas, D., J.M. Betton, and S. Raina. 1996. New components of protein folding in extracytoplasmic compartments of Escherichia coli SurA, FkpA and Skp/OmpH. Mol. Microbiol. 21: 871-884.

Missiakas, D., M. Lemaire, M. Mayer, C. Georgopoulos, and S. Raina. 1997. Modulation of the Escherichia coli $\sigma^{\mathrm{E}}$ (RpoE) heat shock transcription factor activity by the RseA, RseB, and RseC proteins. Mol. Microbiol. 24: 355-372.

M ori, K., W. Ma, M.J. Gething, and J. Sambrook. 1993. A transmembrane protein with a cdc2 $/$ CDC28-related kinase activity is required for signaling from the ER to the nucleus. Cell 74: 743-756.

M orimoto, R.I., P.E. Kroeger, and J.J. Cotto. 1996. The transcriptional regulation of heat shock genes: $A$ plethora of heat shock factors and regulatory conditions. Exs 77: 139-163.

Nakayama, S. and H. Watanabe. 1995. Involvement of cpxA, a sensor of a two-component regulatory system, in the $\mathrm{pH}$ dependent regulation of expression of Shigella sonnei virF gene. J. Bacteriol. 177: 5062-5069.

N eumann, B., A. Pospiech, and H.U. Schairer. 1992. Rapid isolation of genomic DN A from gram-negative bacteria. Trends Genet. 8: 332-333.

N orrander, J., T. Kempe, and J. M essing. 1983. Construction of improved M 13 vectors using oligodeoxynucleotide-directed mutagenesis. Gene 26: 101-106.

Pogliano, J., A.S. Lynch, D. Belin, E.C.C. Lin, and J. Beckwith. 1997. Regulation of Escherichia coli cell envelope proteins involved in protein folding and degradation by the Cpx twocomponent system. Genes \& Dev. 11: 1169-1182.

Pugsley, A.P. 1993. The complete general secretory pathway in gram-negative bacteria. Microbiol. Rev 57: 50-108.

Raina, S., D. Missiakas, and C. Georgopoulos. 1995. The rpoE gene encoding the $\sigma^{\mathrm{E}}\left(\sigma^{24}\right)$ heat shock sigma factor of Escherichia coli. EMBO J. 14: 1043-1055.

Rose, R.E. 1988. The nucleotide sequence of pACYC177. Nucleic Acids Res. 16: 356.

Rouvière, P.E. and C.A. Gross. 1996. SurA, a periplasmic protein with peptidyl-prolyl isomerase activity, participates in the assembly of outer membrane porins. Genes \& Dev. 10: 3170-3182.

Rouvière, P.E., A. De Las Peñas, J. Mecsas, C.Z. Lu, K.E. Rudd, and C.A. Gross. 1995. rpoE, the gene encoding the second heat-shock sigma factor, $\sigma^{\mathrm{E}}$, in Escherichia coli. EMBO J. 14: 1032-1042.

Sambrook, J., E. Fritsch, and T. M aniatis. 1989. Molecular cloning: A laboratory manual. Cold Spring Harbor Laboratory Press, Cold Spring Harbor, NY.

Shamu, C.E., J.S. Cox, and P. Walter. 1994. The unfolded-protein-response pathway in yeast. Trends Cell Biol. 4: 56-60.

Sidrauski, C., J.S. Cox, and P. Walter. 1996. tRN A ligase is required for regulated $\mathrm{mRNA}$ splicing in the unfolded protein response. Cell 87: 405-413.

Singer, M., T.A. Baker, G. Schnitzler, S.M. Deischel, M. Goel, W. Dove, K.J. Jaacks, A.D. Grossman, J.W. Erickson, and C.A. Gross. 1989. A collection of strains containing genetically linked alternating antibiotic resistance elements for genetic mapping of Escherichia coli. Microbiol. Rev. 53: 1-24.

Snyder, W.B., L.J. Davis, P.N. Danese, C.L. Cosma, and T.J. Silhavy. 1995. Overproduction of NIpE, a new outer membrane lipoprotein, suppresses the toxicity of periplasmic LacZ by activation of the Cpx signal transduction pathway. J. Bacteriol. 177: 4216-4223.
Strauch, K.L., K. Johnson, and J. Beckwith. 1989. Characterization of degP, a gene required for proteolysis in the cell envelope and essential for growth of Escherichia coli at high temperature. J. Bacteriol. 171: 2689-2696.

Straus, D.B., W.A. Walter, and C.A. Gross. 1989. The activity of $\sigma^{32}$ is reduced under conditions of excess heat shock protein production in Escherichia coli. Genes \& Dev. 3: 2003-2010.

_- 1990. DnaK, Dnaj, and GrpE heat shock proteins negatively regulate heat shock gene expression by controlling the synthesis and stability of $\sigma^{32}$. Genes \& Dev. 4: 2202-2209.

Thorbjarnardottir, S.H., R.A. M agnusdottir, and G. Eggertsson. 1978. Mutations determining generalized resistance to aminoglycoside antibiotics in Escherichia coli. Mol. \& Gen. Genet. 161: 89-98.

Wang, Q.P. and J.M. Kaguni. 1989. A novel sigma factor is involved in expression of the rpoH gene of Escherichia coli. J. Bacteriol. 171: 4248-4253.

Wu, C. 1995. Heat shock transcription factors: Structure and regulation. Annu. Rev. Cell. Dev. Biol. 11: 441-469.

Yura, T., T. Tobe, K. Ito, and T. Osawa. 1984. Heat shock regulatory gene (htpR) of Escherichia coli is required for growth at high temperature but is dispensable at low temperature. Proc. Natl. Acad. Sci. 81: 6803-6807.

Yura, T., H. N agai, and H. M ori. 1993. Regulation of the heatshock response in bacteria. Annu. Rev. Microbiol. 47: 321350. 


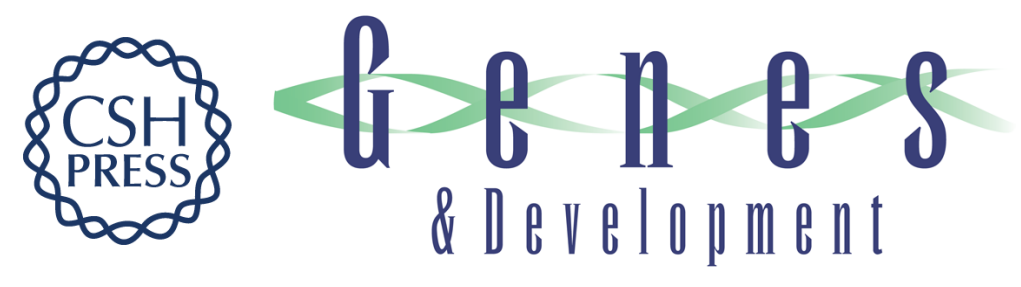

\section{The response to extracytoplasmic stress in Escherichia coli is controlled by partially overlapping pathways}

Lynn Connolly, Alejandro De Las Peñas, Benjamin M. Alba, et al.

Genes Dev. 1997, 11:

Access the most recent version at doi:10.1101/gad.11.15.2012

References This article cites 54 articles, 26 of which can be accessed free at: http://genesdev.cshlp.org/content/11/15/2012.full.html\#ref-list-1

License

Email Alerting

Receive free email alerts when new articles cite this article - sign up in the box at the top Service right corner of the article or click here.

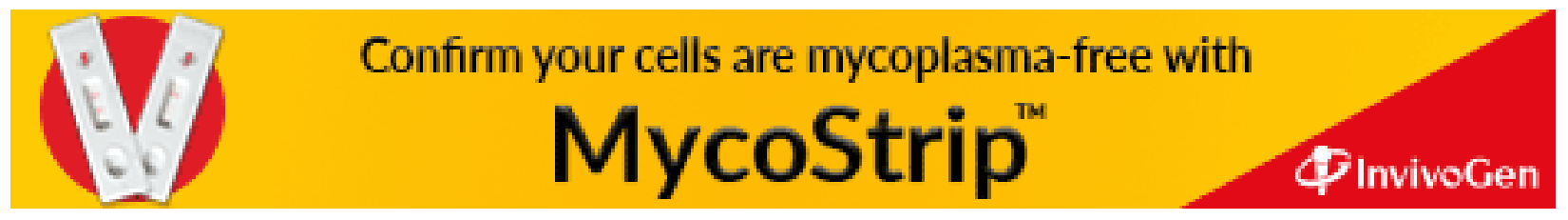

